\title{
Short communication: Detection limits of non- $\beta$-lactam antibiotics in goat's milk by microbiological residues screening tests
}

\author{
D. Sierra, ${ }^{*}$ A. Contreras, $\dagger$ A. Sánchez, $\dagger^{1}$ C. Luengo, ${ }^{*}$ J. C. Corrales, $†$ C. T. Morales, ${ }^{*}$ C. de la Fe, $\dagger$ I. Guirao, ${ }^{*}$ \\ and C. Gonzaloł \\ *Laboratorio Agroalimentario y de Sanidad Animal, Consejería de Agricultura y Agua, Murcia, Spain \\ †Departamento de Sanidad Animal, Facultad de Veterinaria, Universidad de Murcia, 30071 Espinardo, Murcia, Spain \\ ‡Departamento de Producción Animal, Facultad de Veterinaria, Universidad de León, León, Spain
}

\section{ABSTRACT}

This study compares the performance of 4 antimicrobial residue screening tests [brilliant black reduction test AiM (Analytik in Milch Produktions- und Vertriebs GmbH, München, Germany), Delvotest MCS (DSM Food Specialties, Delft, the Netherlands), Eclipse 100 test (ZEU-Inmunotec SL, Zaragoza, Spain), and Copan Milk Test (Copan Italia S.p.a., Brescia, Italy)] used to detect 20 antimicrobial agents (aminoglycosides, macrolides, tetracyclines, sulfonamides, and quinolones) in goat's milk, according to International Dairy Federation guidelines. Composite milk samples from 30 antibioticfree goats were used to prepare spiked milk samples and 11,520 analytical determinations were carried out. According to a logistic regression model, agreement coefficients were greater than $98 \%$ for most of the antibiotics, with higher b values obtained for macrolides. Neither tetracyclines nor quinolones were detected at European Union maximum residue limits. Only the Copan Milk Test and the Delvotest MCS were able to detect 3 antimicrobials below their maximum residue limits (neomycin, tylosin, and sulfadimethoxine). Given that these tests are used in control programs for goat's milk, our results indicate their sensitivity would need to be improved to guarantee safety for consumers.

Key words: goat's milk, residue screening test, antimicrobial, non- $\beta$-lactam

Antimicrobial residues in milk need to be officially controlled because of possible risks for consumers. A wide range of health repercussions caused by excess antimicrobial residues have been described, such as allergic reactions, intestinal dysbiosis, and the creation of a population resistant to bacteria (Allison, 1985; Dewdney et al., 1991). In addition to consequences for the consumers, the presence of antimicrobial residues in

Received February 3, 2009

Accepted June 1, 2009.

${ }^{1}$ Corresponding author: asanlope@um.es milk can generate problems for producers because antimicrobial residues may impair bacterial fermentation processes (Mourot and Loussouarn, 1981) when milk is used to produce fermented products. This problem especially affects sheep's and goat's milk because these are often used to produce cheese. Given the possible repercussions on public health and the dairy industry, official limits exist for antimicrobial residues, and the European Union (EU) legislation (Council Regulation EEC2377/90; European Union, 1990) stipulates maximum residue limits (MRL) for defined antimicrobials. Most antibiotic screening tests (AST) currently available were initially developed to detect $\beta$-lactam antibiotics in cow's milk and are based on inhibiting the growth of Geobacillus stearothermophilus var. calidolactis $(\boldsymbol{G} \boldsymbol{s c})$. Despite $\beta$-lactams being widely used to treat mastitis and other infections, other drugs are often used for antibiotic treatment of infected dairy animals. Thus, in addition to goats and sheep being administered $\beta$-lactams, they are often administered antimicrobial drugs such as macrolides, tetracyclines, or sulfonamides (Menzies, 2000). However, the detection limits (DL) of tests for the different antimicrobials have not yet been determined in goat's milk. The DL of some screening kits for use in sheep's milk have been established by some authors (Althaus et al., 2003; Molina et al., 2003; Montero et al., 2005; Linage et al., 2007), yet most DL available so far are based on results obtained in cow's milk. In some studies conducted in sheep's milk, the brilliant black reduction test (hereafter BRT AiM; Analytik in Milch Produktions- und Vertriebs $\mathrm{GmbH}$, München, Germany; Molina et al. 2003) and the Eclipse 100 test (hereafter Eclipse; ZEU-Inmunotec SL, Zaragoza, Spain; Montero et al., 2005) were unable to detect levels below the EU MRL of antimicrobials from 5 groups of non- $\beta$-lactam antimicrobials (aminoglycosides, macrolides, quinolones, sulfonamides, and tetracyclines). Only the Delvotest MCS (hereafter the Delvotest; DSM Food Specialties, Delft, the Netherlands) and the blue-yellow test (Charm Sciences Inc., Lawrence, MA) have been reported to 
Table 1. List of the antimicrobials used in this study, their commercial reference numbers, and their final concentrations in the spiked milk samples

\begin{tabular}{lll}
\hline Antimicrobial class or agent & Reference no. & Concentrations $(\mu \mathrm{g} / \mathrm{kg})$ \\
\hline Aminoglycosides & & \\
Gentamicin & $\mathrm{G}-3632$ & $0,50,100,200,400,600,800,1,500$ \\
Neomycin & $\mathrm{N}-1876$ & $0,250,500,1,000,1,500,2,000,4,000,8,000$ \\
Spectinomycin & $\mathrm{S}-4114$ & $0,250,500,1,000,1,500,2,000,4,000,8,000$ \\
Streptomycin & $\mathrm{S}-6501$ & $0,250,500,1,000,1,500,2,000,4,000,8,000$ \\
Kanamycin & $\mathrm{K}-4000$ & $0,250,500,1,000,1,500,2,000,4,000,8,000$ \\
Macrolides & & \\
Tylosin & 93806 & $0,10,25,50,75,100,200,300$ \\
Erythromycin & 45673 & $0,25,50,100,200,300,500$ \\
Spyramicin & $\mathrm{S}-9132$ & $0,125,250,500,1,000,2,500,5,000,7,500$ \\
Lincomycin & $\mathrm{L}-6004$ & $0,125,250,500,1,000,2,500,5,000,7,500$ \\
Tetracyclines & & \\
Tetracycline & $\mathrm{T}-3258$ & $0,100,200,400,600,800,1,000,1,200$ \\
Oxytetracycline & $\mathrm{O}-5750$ & $0,100,200,400,600,800,1,000,1,200$ \\
Doxycycline & $\mathrm{D}-9891$ & $0,100,200,400,600,800,1,000,1,200$ \\
Chlortetracycline & $\mathrm{C}-4881$ & $0,4,000,6,000,10,000,15,000,30,000,50,000,75,000$ \\
Sulfonamides & & \\
Sulfadimethoxine & $\mathrm{S}-7385$ & $0,10,25,50,100,200,500,1,000$ \\
Sulfamethazine & $\mathrm{S}-5637$ & $0,50,100,200,400,600,800,1,500$ \\
$\quad$ Sulfanilamide & $\mathrm{S}-9251$ & $0,50,100,200,400,600,800,1,500$ \\
Quinolones & & \\
Enrofloxacin & 17849 & $0,1,000,2,000,3,000,4,000,5,000,6,000,8,000$ \\
Norfloxacin & $\mathrm{N}-9890$ & $0,1,000,2,000,3,000,4,000,5,000,6,000,8,000$ \\
Ciprofloxacin & 17850 & $0,1,000,2,000,3,000,4,000,5,000,6,000,8,000$ \\
Flumequine & $\mathrm{F}-7016$ & $0,10,000,25,000,50,000,75,000,100,000,200,000,300,000$ \\
\hline
\end{tabular}

detect non- $\beta$-lactam antimicrobials below the EU MRL in sheep's milk, including some sulfonamides (Althaus et al., 2003) or tylosin and enrofloxacin (Linage et al., 2007). The objective of this work was to compare the performance of 4 commercial screening tests and determine their DL for 20 non- $\beta$-lactam antimicrobials in goat's milk.

Composite milk samples (200 $\mathrm{mL}$ ) from primiparous goats free of clinical or subclinical IMI (even Mycoplasma spp.), and that had never been administered an antibiotic, were obtained and transported refrigerated to the laboratory the same morning. On arrival, the samples were mixed to obtain antimicrobial-free milk, divided into $100-\mathrm{mL}$ aliquots, and frozen $\left(-20^{\circ} \mathrm{C}\right)$ until used to prepare the antimicrobial spiked samples for the study.

Antimicrobial spiked samples were prepared following the recommendations of the Guidance for the Standardized Evaluation of Microbial Inhibitor Tests (International Dairy Federation, 1999; FIL-IDF Standard No. 183). Twenty non- $\beta$-lactam antibiotics from 5 groups were selected (Table 1). These drugs were stored and handled according to the instructions of the manufacturer before use. Drugs were dissolved (1 mg/ $\mathrm{mL})$ and 8 different dilutions of spiked milk samples were prepared for each antimicrobial, including a blank (Table 1), according to International Dairy Federation (1999) recommendations. All dilutions were prepared in 100-mL volumetric flasks on the day of analysis to avoid problems related to instability. For each antimicrobial, 18 replicates of each dilution were subjected to each of the 4 AST to give a total of 11,520 analytical determinations.

The screening tests assessed were 1) the BRT AiM, 2) the Delvotest, 3) the Eclipse test, and 4) the Copan Milk Test (hereafter the CMT; Copan Italia S.p.a., Brescia, Italy). All these tests are based on inhibiting the growth of spores of Gsc. The test medium is a mixture of nutrients, test bacteria $(G s c)$, a colored indicator (brilliant black for the BRT AiM and bromocresol purple for the other AST), and other supplements. When the milk sample contains no residues or these are below the DL, the spores germinate and grow, and their metabolic activity makes the indicator change color. In the presence of effective concentrations of antimicrobial residues, no bacterial activity will be detected and the indicator color will remain unchanged (blue or purple). The color change can be assessed visually or spectrophotometrically. All AST were carried out in 96-well microtiter plates according to the instructions of the manufacturer. Briefly, the spiked milk samples $(100 \mu \mathrm{L})$ were inoculated in wells containing the culture medium for $G s c$ and a $\mathrm{pH}$ indicator, including a negative and a positive control. The plates were then carefully sealed and placed in a water bath and incubated at $64 \pm 1{ }^{\circ} \mathrm{C}$ for $3 \mathrm{~h}$. Results were separately interpreted visually by 2 technicians for the CMT and spectrophotometrically for the other 3 tests. A spectrophotometer was used at 
Table 2. Logistic regression model variables and detection limits of the antimicrobials obtained using the Delvotest MCS ${ }^{1}$ in goat's milk, considering a binary response variable

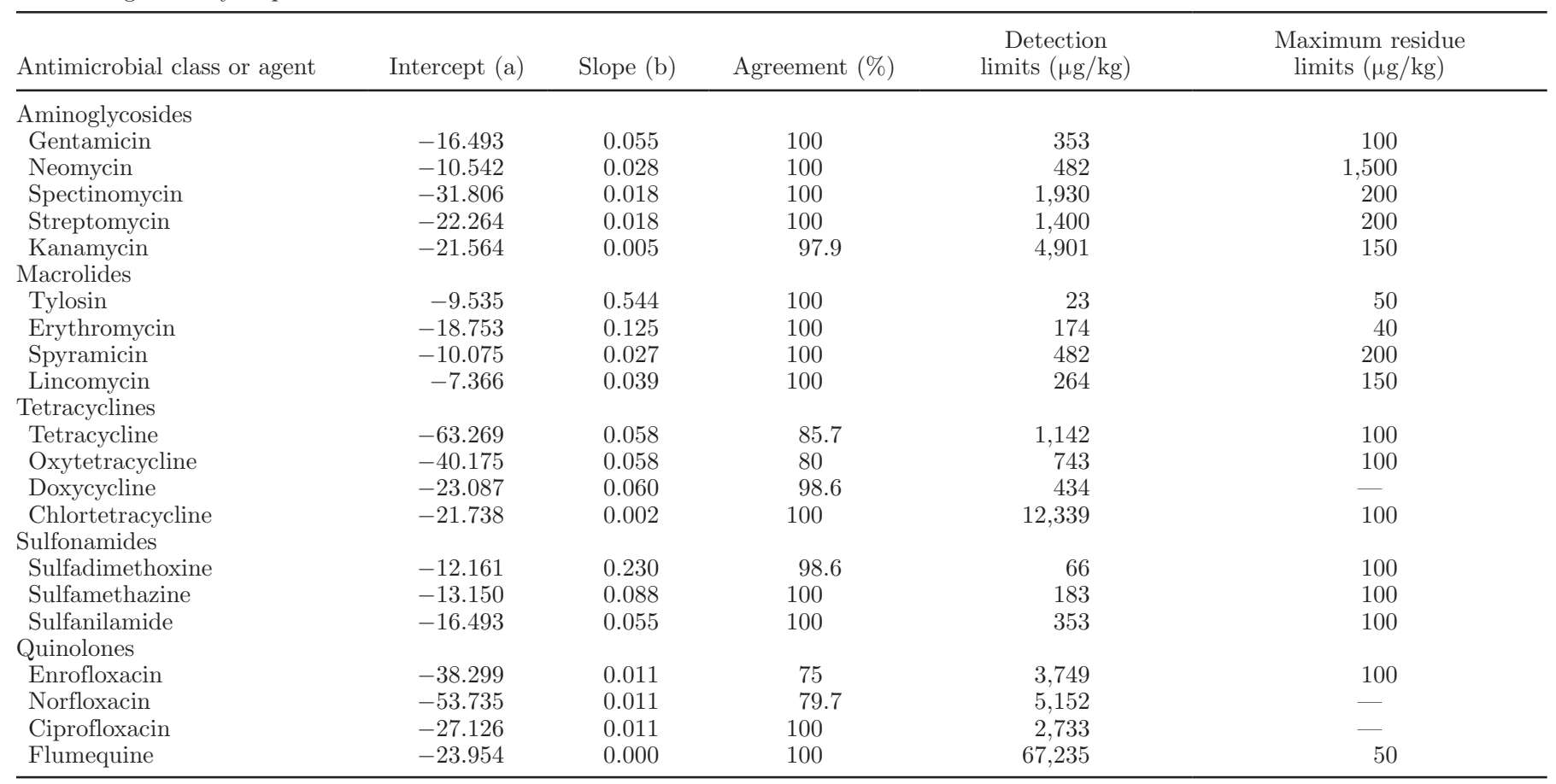

${ }^{1}$ DSM Food Specialties (Delft, the Netherlands).

the measuring and reference wavelengths of 450 and $620 \mathrm{~nm}$, respectively, for the BRT AIM and at the measuring and reference wavelengths of 590 and $650 \mathrm{~nm}$, respectively, for the Eclipse test. A DelvoScan Reader (DSM Food Specialities) was used for the Delvotest.

The DL of each test was determined for each antimicrobial agent by logistic regression using SAS LOGISTIC software (SAS Institute, 1998). The response observed was considered binary and was classified as positive, dubious, or negative. The logistic regression model used was

$$
\mathrm{L}_{\mathrm{ij}}=\operatorname{logit}\left(\mathrm{P}_{\mathrm{ij}}\right)=\mathrm{a}_{0}+\mathrm{bAC}_{\mathrm{i}}+\varepsilon_{\mathrm{ij}},
$$

where logit is the linear logistic model, that is, $\ln \left[\mathrm{P}_{\mathrm{ij}} /(1\right.$ $\left.-\mathrm{P}_{\mathrm{ij}}\right)$ ]; $\mathrm{P}_{\mathrm{ij}}$ is the probability of negative versus positive plus dubious results; AC is the antimicrobial concentration; $\mathrm{a}$ is the intercept; $\mathrm{b}$ is the slope; and $\varepsilon_{\mathrm{ij}}$ is the residual error. Agreement coefficients were estimated as the rank correlation between observed and predicted results (Althaus et al., 2003). The DL was estimated as the concentration at which $95 \%$ of results were positive (International Dairy Federation, 1999). Agreement between technicians visually interpreting results was estimated as the kappa value (Thrusfield, 1995).

Tables 2, 3, 4, and 5 summarize the results of the logistic regression model and provide the DL recorded for the $4 \mathrm{AST}$. Agreement coefficients were greater than $98 \%$ for most of the antibiotics. The exceptions were the sulfanilamide, which showed $66.7 \%$ agreement for the BRT AIM (Table 4); quinolones, which showed agreement coefficients of 75 to $100 \%$ for the $4 \mathrm{AST}$; and some tetracyclines, which showed 80 to $100 \%$ agreement among values obtained by using the Delvotest (Table 2) and BRT AIM (Table 4). These findings indicate that appropriate fitting was achieved between observed and predicted results with the logistic regression model. The coefficient b (slope) of the logistic regression line was closely related to the sensitivity of the screening test for each antimicrobial agent. For all $4 \mathrm{AST}$, the lowest $\mathrm{b}$ values were obtained for the quinolones (0.000 to 0.013$)$ and the highest values were obtained for the macrolides (0.006 to 0.544 ). Most of the antimicrobials were undetectable below or close to their EU MRL, and 14 of the 17 antibiotics with EU MRL could not be detected at levels at or below the MRL when using the 4 AST. In effect, none of the tetracyclines or quinolones was detected at its MRL or close to it. According to the low b values in the logistic regression, the quinolones showed the highest DL of all the antimicrobials for all the tests, which ranged from $1,915 \mu \mathrm{g} / \mathrm{kg}$ (ciprofloxacin with CMT) to $93,168 \mu \mathrm{g} / \mathrm{kg}$ (flumequine with Eclipse). None of the antimicrobials studied was detected at or below the MRL when using 
Table 3. Logistic regression model variables and detection limits of the antimicrobials obtained using the Copan Milk Test ${ }^{1}$ in goat's milk, considering a binary response variable

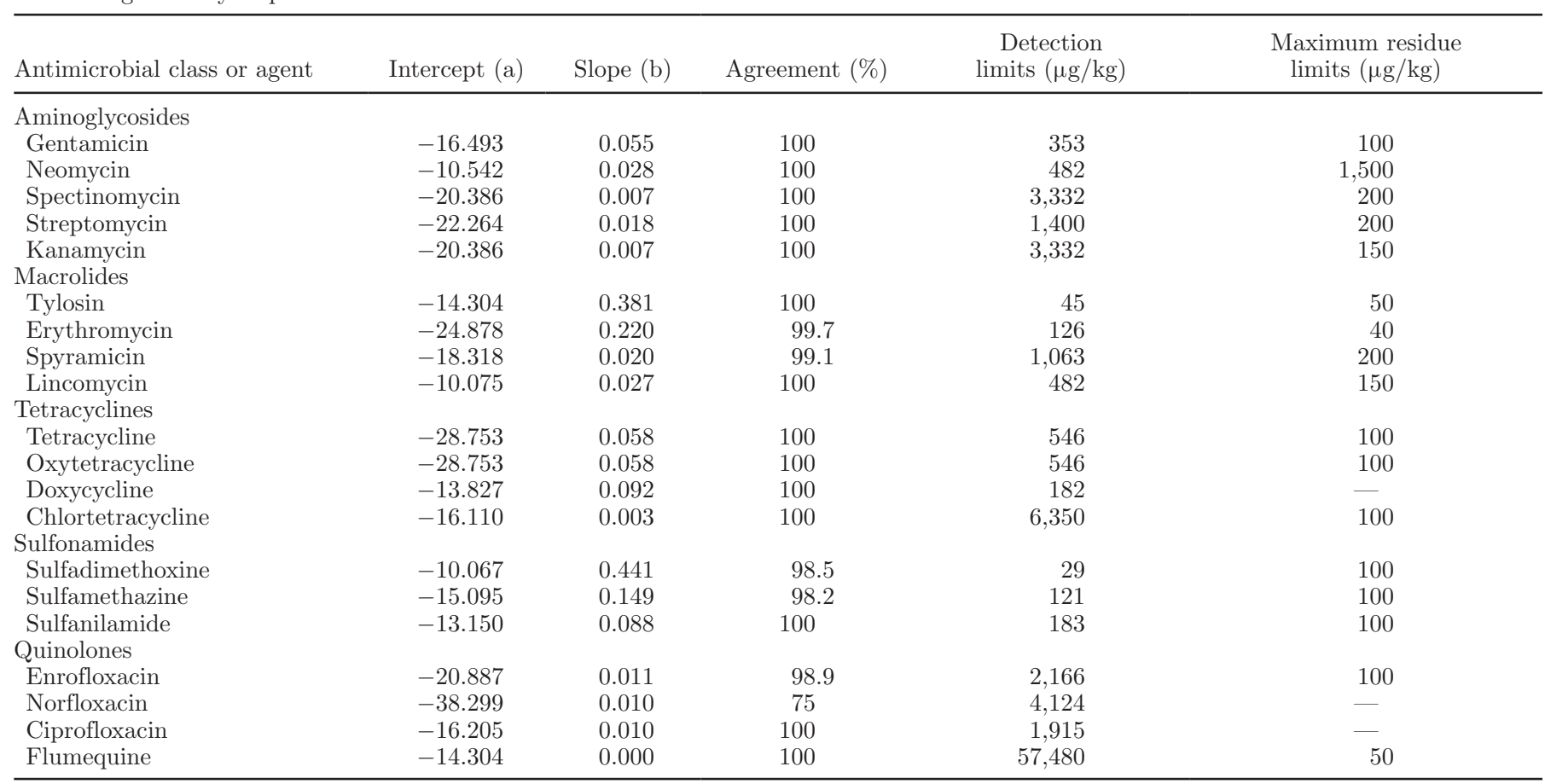

${ }^{1}$ Copan Italia S.p.a. (Brescia, Italy).

the Eclipse test, and only 3 antimicrobials (neomycin, tylosin, and sulfadimethoxine) were detected below their MRL when using some of the other AST. Tylosin and sulfadimethoxine were appropriately detected using 2 of the tests, and neomycin was detected with all 3 AST. When the Delvotest and CMT were used, the DL were, respectively, 23 and $45 \mu \mathrm{g} / \mathrm{kg}$ for tylosin and 66 and $29 \mu \mathrm{g} / \mathrm{kg}$ for sulfadimethoxine. Neomycin was detected below the EU MRL $(1,500 \mu \mathrm{g} / \mathrm{kg})$ by 3 of the tests: the Delvotest and CMT (482 $\mu \mathrm{g} / \mathrm{kg}$, respectively) and the BRT AIM $(909 \mu \mathrm{g} / \mathrm{kg})$. Figures 1, 2, 3, and 4 depict the performance of the 4 AST, as recommended by the International Dairy Federation (1999), for the antimicrobials that yielded the best results (aminoglycosides, macrolides, and sulfonamides). Thus, the ideal test should be capable of detecting $1 \times \mathrm{MRL}$ of all antimicrobials of concern, which is indicated in the figures by the middle circle. The DL of the test under study is indicated by the circle in bold. The patterns show that none of the 4 tests came close to fulfilling International Dairy Federation criteria for the ideal AST. Despite this, it can be easily observed that the Delvotest and CMT yielded the best results and were similarly able to detect 3 antimicrobials below their MRL (neomycin, tylosin, and sulfadimethoxine).

The Delvotest is a simple, fast, and low-cost AST that is widely used to detect antimicrobial residues in the milk of both cows and small ruminants (Zeng et al., 1996; Althaus et al., 2003; Yamaki et al., 2004), although information on its use in goat's and sheep's milk is still lacking. In a recent study, Stead et al. (2008) validated the use of the Delvotest SP-NT in cow's milk and detected $2 \beta$-lactam antimicrobials above the EU MRL (oxytetracycline and erythromycin). In sheep's milk, Althaus et al. (2003) reported good results for this test in detecting sulfonamides such as sulfadiazine, sulfamethoxazole, and sulfaquinoxaline below the EU MRL, but with no other groups of antimicrobials, including aminoglycosides (streptomycin, gentamicin, and neomycin), macrolides (erythromycin and tylosin), and tetracyclines (doxycycline, oxytetracycline, and tetracycline). Our results differ from those of Althaus et al. (2003) because we detected neomycin, tylosin, and sulfadimethoxine below their EU MRL when using the Delvotest in goat milk samples (Table 2, Figure 1).

Unlike the other AST used in this study, no previous data are available concerning the use of the CMT in the milk of small ruminants. Using this test for cow's milk, Le Breton et al. (2007) detected sulfamethazine, sulfadiazine, and gentamicin levels at or below the EU MRL but failed to detect other antimicrobials, such as oxytetracycline and dihydrostreptomycin. Because in our study the results of the CMT were read visually, we conducted a preliminary evaluation to check the agree- 
Table 4. Logistic regression model variables and detection limits of the antimicrobials obtained using the brilliant black reduction test ${ }^{1}$ in goat's milk, considering a binary response variable

\begin{tabular}{|c|c|c|c|c|c|}
\hline Antimicrobial class or agent & Intercept (a) & Slope (b) & Agreement (\%) & Detection limits $(\mu \mathrm{g} / \mathrm{kg})$ & $\begin{array}{l}\text { Maximum residue } \\
\text { limits }(\mu \mathrm{g} / \mathrm{kg})\end{array}$ \\
\hline \multicolumn{6}{|l|}{ Aminoglycosides } \\
\hline Spectinomycin & -8.794 & 0.002 & 98.5 & 5,867 & 200 \\
\hline Streptomycin & -22.264 & 0.018 & 100 & 1,400 & 200 \\
\hline Kanamycin & -21.776 & 0.004 & 100 & 6,179 & 150 \\
\hline Erythromycin & -18.753 & 0.125 & 100 & 174 & 40 \\
\hline Spyramicin & -10.075 & 0.027 & 100 & 482 & 200 \\
\hline Lincomycin & -7.366 & 0.039 & 100 & 264 & 150 \\
\hline \multicolumn{6}{|l|}{ Tetracyclines } \\
\hline Tetracycline & -63.269 & 0.058 & 85.7 & 1,142 & 100 \\
\hline Oxytetracycline & -63.269 & 0.058 & 85.7 & 1,142 & 100 \\
\hline Doxycycline & -40.175 & 0.058 & 80 & 743 & - \\
\hline \multicolumn{6}{|l|}{ Sulfonamides } \\
\hline \multicolumn{6}{|l|}{ Quinolones } \\
\hline Enrofloxacin & -38.299 & 0.011 & 75 & 3,749 & 100 \\
\hline Norfloxacin & -44.891 & 0.006 & 85.7 & 7,972 & - \\
\hline Ciprofloxacin & -29.391 & 0.013 & 99.6 & 2,487 & - \\
\hline Flumequine & -30.992 & 0.000 & 98.6 & 84,830 & 50 \\
\hline
\end{tabular}

${ }^{1}$ Analytik in Milch Produktions- und Vertriebs GmbH (München, Germany).

ment between technicians and we obtained a kappa coefficient of 1 , indicating full agreement. Similar to the Delvotest discussed above, the CMT was able to detect neomycin, tylosin, and sulfadimethoxine below their stipulated EU MRL (Table 3, Figure 2).

The BRT AIM is another microorganism inhibitionbased AST that is widely used for the detection of antimicrobial residues in milk, and it has been marketed

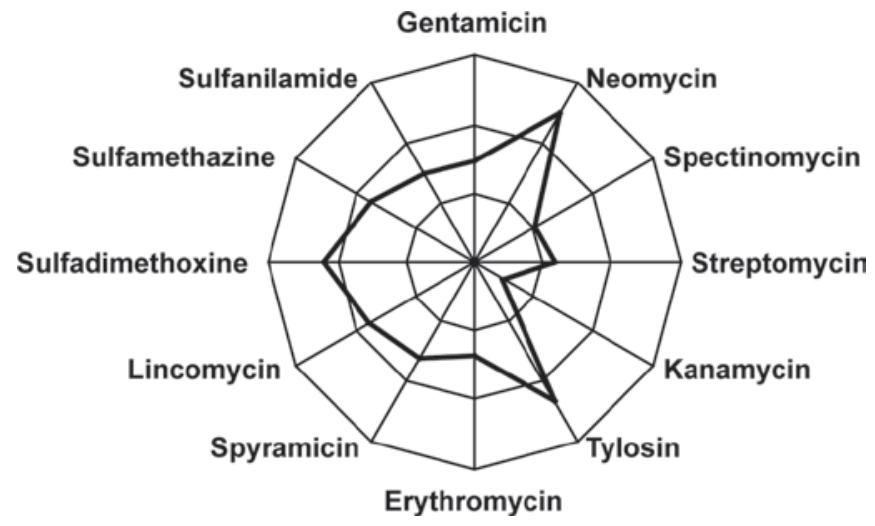

Figure 1. Detection pattern obtained for the Delvotest MCS (DSM Food Specialties, Delft, the Netherlands) when used to detect residues of aminoglycosides, macrolides, and sulfonamides. Detection limits are indicated as n-fold the European Union maximum residue limits, expressed in micrograms per kilogram (inner circle, $\geq 10 \times$; middle circle, $1 \times$; outer circle, $0.1 \times)$. by different manufacturers under several trade names. Despite numerous studies describing the DL of this test for antibiotic residues in cow's milk, few studies have assessed the use of the BRT AIM in sheep's milk and none has been reported for goat's milk. Thus, in sheep's milk Molina et al. (2003) examined the use of the BRT AiM for 13 non- $\beta$-lactam antimicrobials (aminoglycosides, macrolides, sulfonamides, tetracyclines, and

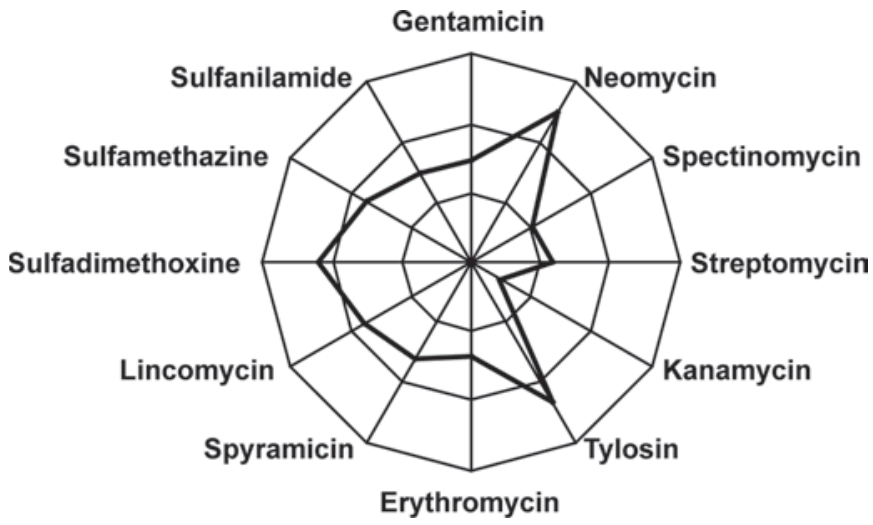

Figure 2. Detection pattern obtained for the Copan Milk Test (Copan Italia S.p.a., Brescia, Italy) when used to detect residues of aminoglycosides, macrolides, and sulfonamides. Detection limits are indicated as n-fold the European Union maximum residue limits, expressed in micrograms per kilogram (inner circle, $\geq 10 \times$; middle circle, $1 \times$; outer circle, $0.1 \times$ ). 
Table 5. Logistic regression model variables and detection limits of the antimicrobials obtained using the Eclipse 100 test $^{1}$ in $_{\text {goat's }}$ milk, considering a binary response variable

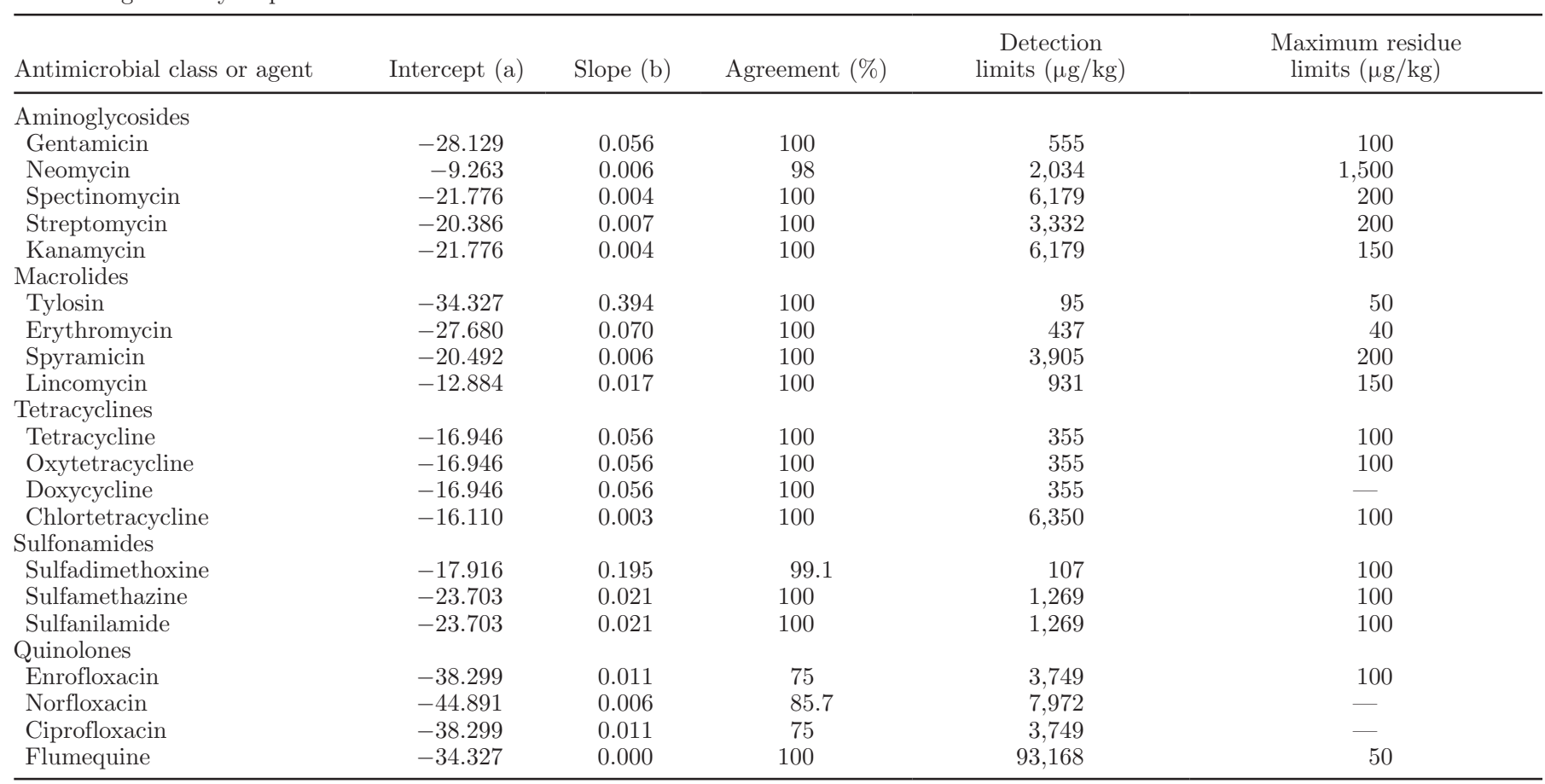

${ }^{1}$ ZEU-Inmunotec SL (Zaragoza, Spain).

others) but were unable to detect them at or below the EU MRL. In our study, the BRT AiM was able to detect only neomycin below its permitted MRL (Table 4, Figure 3).

Finally, the Eclipse test could not detect any of the antimicrobials examined here at or below their MRL (Table 5, Figure 4). The Eclipse test was developed for

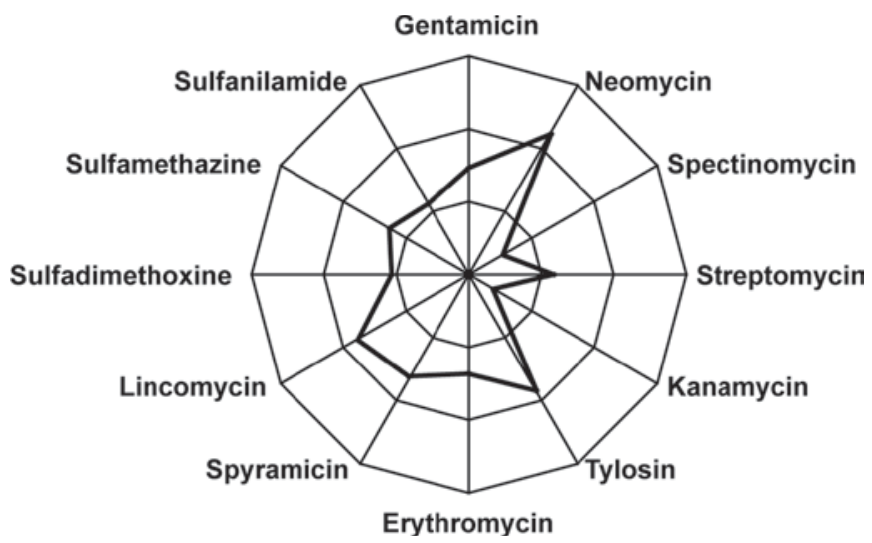

Figure 3. Detection pattern obtained for the brilliant black reduction test (Analytik in Milch Produktions- und Vertriebs GmbH, München, Germany) when used to detect residues of aminoglycosides, macrolides, and sulfonamides. Detection limits are indicated as nfold the European Union maximum residue limits, expressed in micrograms per kilogram (inner circle, $\geq 10 \times$; middle circle, $1 \times$; outer circle, $0.1 \times)$. use in cow's and sheep's milk. Montero et al. (2005) used this test in sheep's milk to establish its DL for 17 antimicrobials from 5 groups (aminoglycosides, macrolides, quinolones, sulfonamides, and tetracyclines) and also failed to detect them at or below the EU MRL.

The failure of AST to detect most of these antimicrobials at or below their MRL is no surprise because

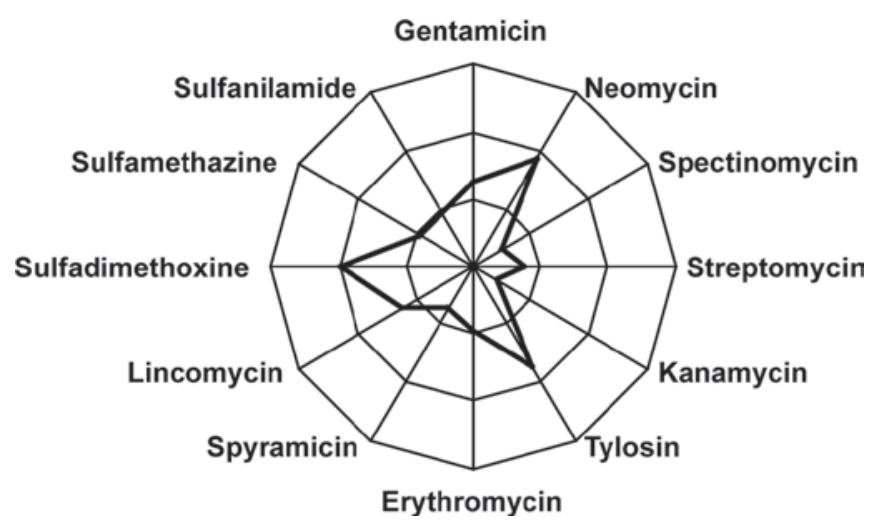

Figure 4. Detection pattern obtained for the Eclipse 100 test (ZEU-Inmunotec SL, Zaragoza, Spain) when used to detect residues of aminoglycosides, macrolides, and sulfonamides. Detection limits are indicated as n-fold the European Union maximum residue limits, expressed in micrograms per kilogram (inner circle, $\geq 10 \times$; middle circle, $1 \times$; outer circle, $0.1 \times$ ). 
these tests were developed to detect $\beta$-lactams based on their ability to inhibit Gsc spore outgrowth. Nevertheless, it is important to know the performance of the AST in detecting non- $\beta$-lactam antimicrobials because these antimicrobials are routinely used in goats and other dairy ruminants. Thus, laboratories conducting microbiological AST should complement these with more specific methods capable of detecting groups of antimicrobials other than $\beta$-lactam antibiotic residues.

In conclusion, when used in goat's milk, the antimicrobial residue screening tests examined here failed to detect most of the non- $\beta$-lactam antimicrobials tested. Only 3 antimicrobials (neomycin, tylosin, and sulfadimethoxine) were detected below their EU MRL by 2 tests (the Delvotest and the CMT); neither tetracyclines nor quinolones were detected by any of the 4 tests. Our findings point to a need to improve the sensitivity of these methods routinely used as screening tests in antimicrobial residue programs to guarantee consumer safety, given the wide use of non- $\beta$-lactam antimicrobials in goats.

\section{ACKNOWLEDGMENTS}

This study was supported by project AGL200603105GAN, financed by the Dirección General de Investigación (Spanish Ministry of Education and Science, Madrid) and Project 05693/PI/07, financed by the Fundación SENECA (Agencia Regional de Ciencia y Tecnología de la Región de Murcia, Murcia, Spain).

\section{REFERENCES}

Allison, J. R. D. 1985. Antibiotic residues in milk. Br. Vet. J. 141:916.

Althaus, R. L., A. Torres, A. Montero, S. Balasch, and M. P. Molina. 2003. Detection limits of antimicrobials in ewe milk by Delvotest photometric measurements. J. Dairy Sci. 86:457-463.

Dewdney, J. M., L. Maes, J. P. Raynaud, F. Blanc, J. P. Scheid, T. Jackson, S. Lens, and C. Verschueren. 1991. Risk assessment of antibiotic residues of $\beta$-lactams and macrolides in food-products with regard to their immunoallergic potential. Food Chem. Toxicol. 29:477-483.

European Union. 1990. Council Regulation (EEC) No. 2377/90 of 26 June 1990 laying down a Community procedure for the establishment of maximum residue limits of veterinary medical products in foodstuffs of animal origin. Off. J. L 224:1-8.

International Dairy Federation. 1999. Guidance for the standardized evaluation of microbial inhibitors test. FIL-IDF Standard 183. Fed. Int. Laiterie-Int. Dairy Fed., Brussels, Belgium.

Le Breton, M. H., M. C. Savoy-Perroud, and J. M. Diserens. 2007. Validation and comparison of the Copan milk test and Delvotest SP-NT for the detection of antimicrobials in milk. Anal. Chim. Acta 586:280-283.

Linage, B., C. Gonzalo, J. A. Carriedo, J. A. Asensio, M. A. Blanco, L. F. De La Fuente, and F. San Primitivo. 2007. Performance of blue-yellow screening test for antimicrobial detection in ovine milk . J. Dairy Sci. 90:5374-5379.

Menzies, P. I. 2000. Antimicrobial drug use in sheep and goats. Pages 591-601 in Antimicrobial Therapy in Veterinary Medicine. 3rd ed. J. F. Prescott, J. D. Baggot, and R. D. Walker, ed. Iowa State Press, Ames.

Molina, M. P., R. L. Althaus, A. Molina, A. Torres, and N. Fernández. 2003. Antimicrobial agent detection in ewe milk by the microbial inhibitor test (Brilliant Black Reduction Test-BRT-AiM). Int. Dairy J. 13:821-826.

Montero, A., R. L. Althaus, A. Molina, I. Berruga, and M. P. Molina. 2005. Detection of antimicrobial agents by a specific microbiological method (Eclipse 100) for ewe milk. Small Rumin. Res. 57:229237.

Mourot, D., and S. Loussouarn. 1981. Sensibilité des ferments lactiques aux antibiotiques utilisés en médicine vétérinaire. Rec. Med. Vet. (Kiev) 157:175-177.

SAS Institute. 1998. SAS/STAT Software: Changes and Enhancements Through Release 6.11. SAS Inst. Inc., Cary, NC.

Stead, S. L., H. Ashwin, S. F. Richmond, M. Sharman, P. C. Langeveld, J. P. Barendse, J. Stark, and B. J. Keely. 2008. Evaluation and validation according to international standards of the Delvotest SP-NT screening assay for antimicrobial drugs in milk. Int. Dairy J. $18: 3-11$.

Thrusfield, M. 1995. Veterinary Epidemiology. 2nd ed. Blackwell Science Ltd., Oxford, UK.

Yamaki, M., M. I. Berruga, R. L. Althaus, M. P. Molina, and A Molina. 2004. Occurrence of antibiotic residues in milk from Manchega ewe dairy farms. J. Dairy Sci. 87:3132-3137.

Zeng, S. S., E. N. Escobar, and I. Brown-Crowder. 1996. Evaluation of screening tests for detection of antibiotic residues in goat milk Small Rumin. Res. 21:155-160. 